\title{
Numerical comparisons of the thermal behaviour of air and refrigerants in the vortex
}

\author{
tube \\ Zheng Wang ${ }^{1 *}$, K O Suen ${ }^{2}$ \\ 1 School of Civil Engineering and Architecture, Zhejiang Sci-Tech University, Hangzhou, China, 310018, \\ (zheng.wang.13@ucl.ac.uk) \\ 2 Department of Mechanical Engineering, University College London, \\ London, United Kingdom. WC1E 7JE
}

\begin{abstract}
Vortex tubes (VT), as a temperature separation device, have been widely used in open systems in which air is commonly used. When a VT is employed in a closed system, other working fluids could be considered. This paper numerically compares the thermal behaviour of air and two refrigerants (R134a and R600) in a VT under a range of operating conditions. It analyses their cooling and heating effect, the shear stress, flow streamlines patterns and temperature distributions. The results show that the refrigerants share certain similar trends with air: a higher VT inlet pressure leads to an increase in cooling effect that would reach a peak value when the chamber inlet/nozzle outlet velocity gets chocked. However, a larger VT pressure drop (between VT inlet and hot end) may result in a lower heating effect for refrigerants but not for air. A higher VT inlet pressure produces a larger pressure drop and this leads to a bigger temperature drop associated with the expansion process to partially or wholly cancel the temperature increase from the rotating process.
\end{abstract}

Key words: vortex tube, numerical simulation, R134a, R600, cooling effect, heating effect, temperature cancelling

\section{Nomenclature}

$\begin{array}{ll}\text { CS } & \text { Cross section } \\ C O P & \text { Coefficient of performance } \\ h & \text { Specific enthalpy }(\mathrm{kJ} / \mathrm{kg}) \\ k & \text { Turbulence kinetic energy }\left(\mathrm{m}^{2} / \mathrm{s}^{2}\right) \\ \dot{m} & \text { Mass flow rate }(\mathrm{g} / \mathrm{s}) \\ p & \text { Pressure }(\mathrm{kPa} \& \mathrm{bar}) \\ Q & \text { Heat quantity }(\mathrm{W}) \\ T & \text { Temperature }\left({ }^{\circ} \mathrm{C}\right) \\ \text { TSE } & \text { Temperature separation effect }\left({ }^{\circ} \mathrm{C}\right) \\ \text { VT } & \text { Vortex tube } \\ \Delta T_{\mathrm{c}} & \left(T_{\text {in }}-T_{\mathrm{c}}\right), \text { cooling effect }\left({ }^{\circ} \mathrm{C}\right) \\ \Delta T_{\mathrm{h}} & \left(T_{\mathrm{h}}-T_{\mathrm{in}}\right), \text { heating effect }\left({ }^{\circ} \mathrm{C}\right) \\ v & \text { Velocity }(\mathrm{m} / \mathrm{s})\end{array}$

$\mu_{\mathrm{c}} \quad \dot{m}_{\mathrm{c}} / \dot{m}_{\text {in }}$, Cold mass flow ratio

Subscripts

c Cold stream, cold end

h Hot stream, hot end

in Inlet

cham Vortex chamber

$\mathrm{t} \quad$ Turbulent, tangential

w wall

Greek letters

$\varepsilon \quad$ Dissipation rate $\left(\mathrm{m}^{2} / \mathrm{s}^{3}\right)$

$\tau \quad$ Shear stress

1 Introduction

When a high-pressure gas enters a VT (Figure 1), it accelerates through the nozzle to approaching sonic speed. In the vortex chamber, this gas rotates along the peripheral (as the primary flow) in the chamber towards the hot end. Part of this exits the hot end as the hot stream. The rest rebounds (as the secondary flow) by the hot throttle and flows towards the cold end through the cold orifice, forming the cold stream. The hot end pressure (cold mass flow ratio) could be controlled by adjusting the position of the hot throttle or/and the system pressures.

In the past decades, VT have been widely used in open systems, and a large number of VT researches were conducted using air ${ }^{[1]}$. Among them, some studied the operating conditions' influence on the VT temperature separation effect (TSE). 


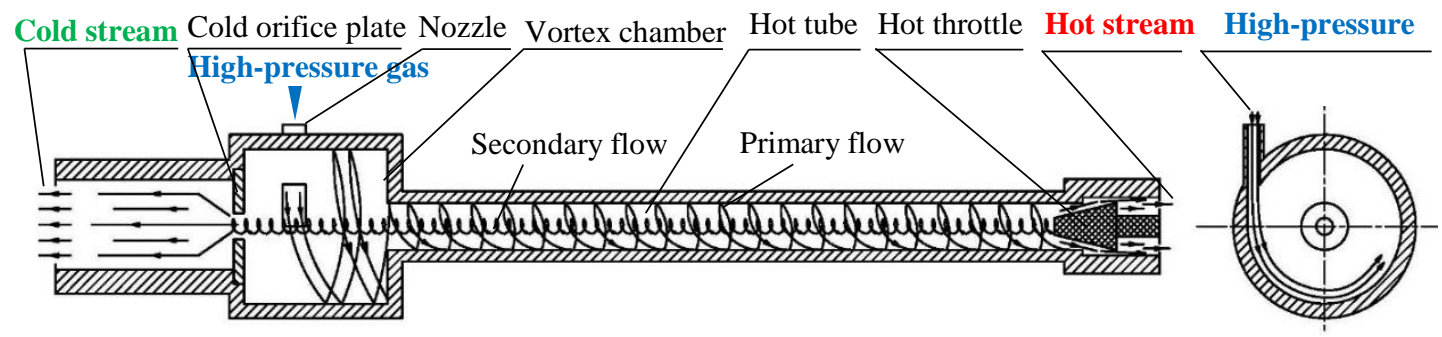

Figure 1 Schematic structure of a VT

At a constant VT inlet air temperature $\left(T_{\text {in }}\right)$, an increase of the VT inlet pressure $\left(p_{\text {in }}\right)$ is observed to lead to an increase of the cooling or heating effect ${ }^{[2-4]}$. This is due to a higher velocity produced at the chamber inlet, which leads to a bigger momentum transfer from the centre to the peripheral of the rotation flow and producing an increased $\mathrm{TSE}^{[3]}$. However, this increased TSE would reach a limit when the chamber inlet gets chocked or reaches sonic conditions ${ }^{[5,6]}$. The change of VT $T_{\text {in }}$ would affect the fluid properties entering to the VT. At a fixed air $p_{\text {in, }}$ either a higher or lower TSE has been experimentally observed when $T_{\text {in }}$ is increased ${ }^{[7,8]}$. The cold mass flow ratio $\mu_{\mathrm{c}}$, another important operating parameter, determines if the VT is to function as a cooling or heating device. In general, a small $\mu_{\mathrm{c}}(<0.5)$ contributes to producing relatively more cooling effect, while a large $\mu_{\mathrm{c}}$ is observed to produce more heating effect ${ }^{[9-11]}$.

When a VT is integrated into closed thermal systems, its TSE could potentially be utilised to improve system efficiency. A possible VT cooling system was suggested by Zhu ${ }^{[12]}$ (Figure 2). Adding the VT essentially turns a single stage compression system into a multi-pressure system, and the cold stream (6b to $7 \mathrm{~b}$ ) of the VT subcools the saturated liquid from the gas-liquid separator at the intermediate pressure (5a to 6a) thus increasing the specific refrigerating effect. This might bring a higher cooling capacity and $C O P$, depending on the conditions.

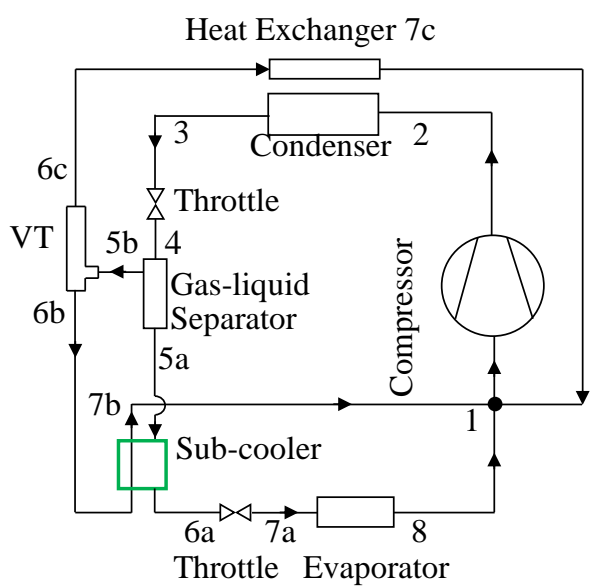

a

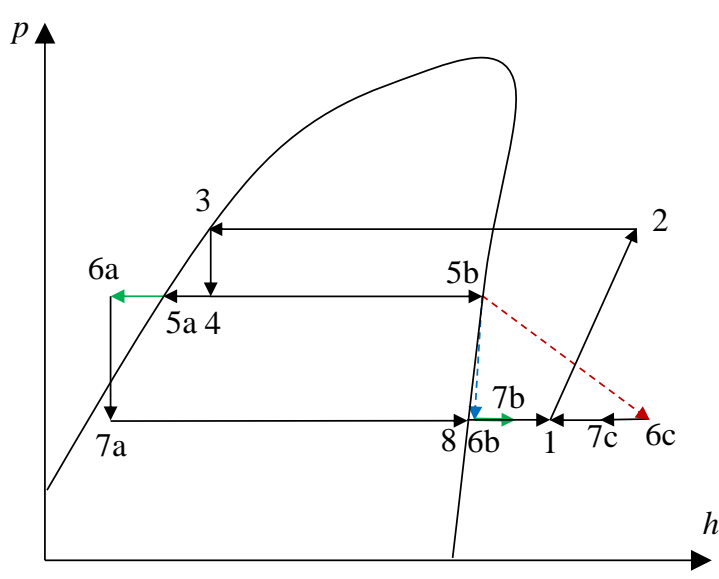

b

Figure 2 Schematic diagram of a possible VT compression cooling system (a) and its flow process on the $p-h$ diagram $(b)^{[12]}$

With closed systems, more fluid choices, such as refrigerants (HFCs, HCs, etc.), can be considered. However, compared to air, published research on refrigerants is relatively limited, and most work focussed on studying the TSE of fluids at a given condition. Martynovskii and Alekseev ${ }^{[13]}$ experimentally compared the cooling effect of several fluids at the same $\mu_{\mathrm{c}}$ of 0.4 . Their results showed R50 $\left(\mathrm{CH}_{4}\right)$ has a better cooling effect than R744 $\left(\mathrm{CO}_{2}\right)$ and R717 $\left(\mathrm{NH}_{3}\right)$. Han et al. ${ }^{[14]}$ investigated the TSE (at $p_{\text {in }}=3$ bar, $\left.T_{\text {in }}=12{ }^{\circ} \mathrm{C}\right)$ of R728 $\left(\mathrm{N}_{2}\right), \mathrm{R} 744$, and some HFCs (R32, R161, R22 and R134a). They noticed that R32 has the best cooling effect $\left(7.18^{\circ} \mathrm{C}\right)$ while R728 has the largest heating effect $\left(3.65^{\circ} \mathrm{C}\right)$. In addition, they observed a negative heating effect, i.e. the hot stream temperature is lower than the inlet. $\mathrm{Zhu}^{[12]}$ also observed the negative heating effect in his experiments on air and R134a. He stated that at his test conditions, R134a is close to the saturation dome and its isothermal 
lines on the $p-h$ diagram have a negative slope, thus a large specific enthalpy increase from the inlet to hot end must be provided to produce the heating effect.

CFD is a poplar research tool used to study the detailed flow behaviour inside the VT. Frohlingsdorf and Unger ${ }^{[15]}$, using Fluent, observed a circulating secondary flow in the VT. The flow receives the energy from the cold air at the VT core and transfers it outwards to the hot air. Karimi-Esfahani et al. ${ }^{[16]}$, also using Fluent, optimized a VT's dimensions and operating conditions for producing the largest cooling effect. Aljuwayhel et al. ${ }^{[17]}$ examined the influence of the VT dimensions $\left(L_{\mathrm{VT}}\right.$ and $\left.\Phi_{\text {cham }}\right)$ on the TSE for air. Behera et al. ${ }^{[18]}$ used the Star-CD code to perform a 3-D simulation and analyse the flow fields and the energy separation mechanism inside the VT.

Being deviate further from ideal gas behaviour, when compared to air, refrigerants are expected to exhibit certain unique VT characteristics. Identification/understanding of these characteristics could help researchers to better choose the operating conditions for refrigerants to acquire better TSE, especially in closed systems. Therefore, this study numerically compares the thermal behaviour of air and two refrigerants in a VT under a range of operating conditions. One (R134a) is chosen from HFC refrigerant group and the other (R600) from $\mathrm{HC}$ group, and both are commercially being used in RAC systems. The velocity profiles, streamlines, temperature and shear stress distributions in the VT generated by simulation code Fluent are analysed. The realgas model of refrigerants is chosen in defining properties in this study. The unique thermal features of air and refrigerants in VT are compared and discussed.

\section{Numerical model}

\subsection{Model geometry}

The chosen geometry is based on primarily the VT dimensions of Aljuwayhel et al. ${ }^{[17]}$, as they provide a comprehensive set of measured data suitable for validation. At the same time, their hot throttle is set up as an annular exit thus allowing the $\mu_{\mathrm{c}}$ be adjusted easily by changing the hot end pressure. As in their work, a 2-D model is used, with the key dimensions given in Figure 3.

The axisymmetric swirl option is chosen in the Fluent code, and an axial annular inlet with specified axial, radial and tangential velocity components is adopted. A $25 \mathrm{~mm}$ extension is added to match the current model with their experimental set up, which was incorporated to allow temperature measurements. A similar extension was observed in Shamsoddini and Khorasani's ${ }^{[19]}$ CFD work which was also based on Aljuwayhel et al.'s work.

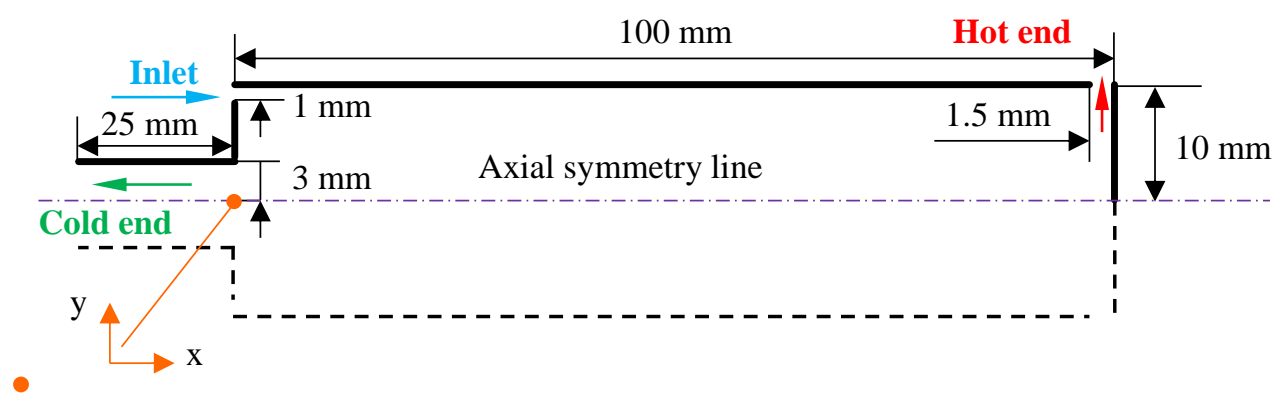

Figure 3 VT geometry and dimensions

\subsection{Mesh number and turbulence model selection}

Five turbulence models (the standard $k-\varepsilon$ model, the $R N G k-\varepsilon$ model with swirl option, the $R N G k-\varepsilon$ model without swirl option, the standard $k-\omega$ model, the SST $k-\omega$ model) are trialled as they have been identified as having the ability to produce a good match between simulated and experimental results ${ }^{[15,16,20,21]}$. The standard wall functions in Ansys Fluent are used which is based on the work of Launder and Spalding ${ }^{[22]}$, as used by others VT researchers ${ }^{[23,24]}$. Eight mesh densities using the quadrilateral pattern are tested and the results for air $\left(\Delta T_{\mathrm{c}}, \Delta T_{\mathrm{h}}\right.$ and relative variation) are presented in Table $1 . \dot{m}_{\mathrm{in}}$ is set at $3.9 \mathrm{~g} / \mathrm{s}$, cold end pressure $p_{\mathrm{c}}$ at $1 \mathrm{~atm}$ and $\mu_{\mathrm{c}}$ at 0.2 . When the number of meshing elements is increased from 30000 to 160000 (at an interval of $\approx 20$ 000), the incremental changes $(\Delta)$ for all models keep decreasing to well below $0.1{ }^{\circ} \mathrm{C}$. 
Table 1 Variations of CFD simulated $\Delta T_{\mathrm{c}}, \Delta T_{\mathrm{h}}$ and relative variation with meshing numbers for $k-\varepsilon$ standard, $k-\varepsilon R N G, k-\varepsilon R N G$ (swirl), $k-\omega$ standard and $k-\omega S S T$ turbulence models

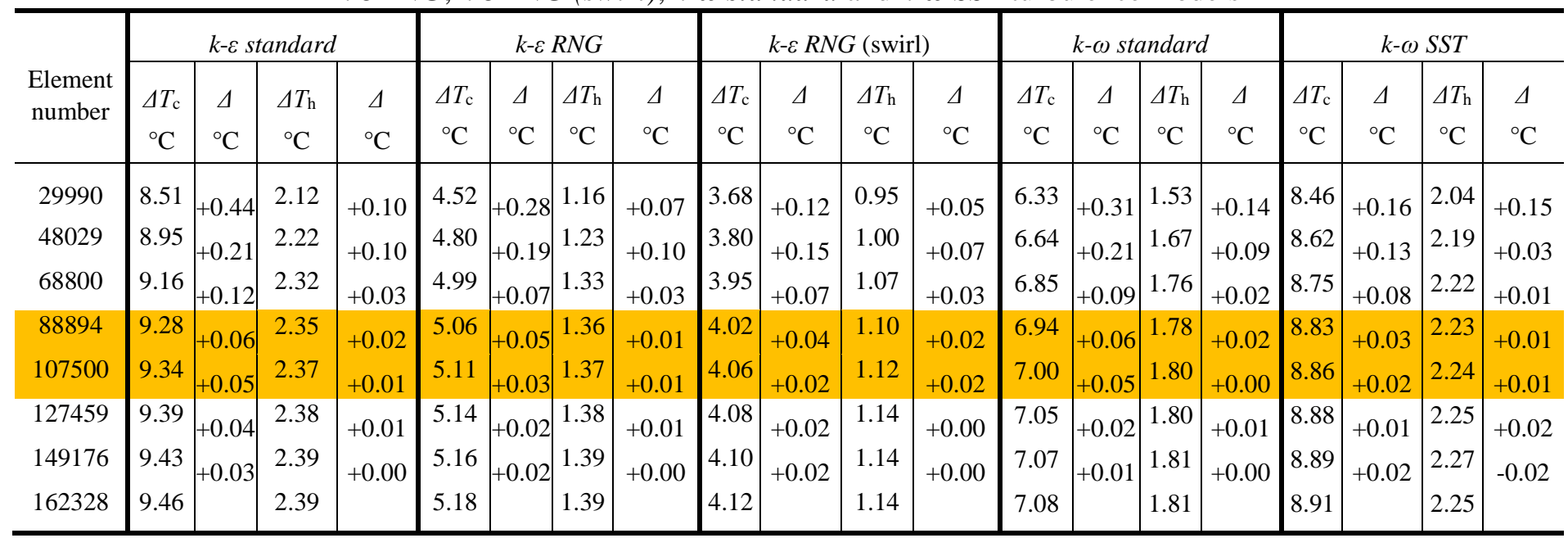

The meshing element number around 90000 is chosen, as it represents a good compromise between accuracy and computer run time. Further increases from 90000 to 110000 leads to only small changes in the results, but almost double the run time.

The results for two $\mu_{\mathrm{c}}$ (Table 2) are shown and compared to Aljuwayhel et al.' ${ }^{[17]}$ experimental data. Both the standard $k-\varepsilon$ and the SST $k-\omega$ models are found to match well with the experimental results. However, the computer run time for the former is three times less, and hence the standard $k-\varepsilon$ model is used in this study.

Table 2 Comparison of simulated results and experiment results $\left(T_{i n}=22{ }^{\circ} \mathrm{C}, p_{\mathrm{c}}=1 \mathrm{bar}\right.$, air $)$

\begin{tabular}{|c|c|c|c|c|c|}
\hline Selected model & $\mu_{\mathrm{c}}$ & $\begin{array}{c}\dot{m}_{\text {in }} \\
\mathrm{kg} / \mathrm{s}\end{array}$ & $\begin{array}{c}\Delta T_{\mathrm{c}} \\
{ }^{\circ} \mathrm{C}\end{array}$ & $\begin{array}{c}\Delta T_{\mathrm{h}} \\
{ }^{\circ} \mathrm{C}\end{array}$ & $\begin{array}{l}p_{\mathrm{h}, \mathrm{sta}} \\
\mathrm{kPa}\end{array}$ \\
\hline \multirow{2}{*}{ Experiment $^{[17]}$} & 0.2 & $3.9 \pm 0.1$ & $9.4 \pm 0.2$ & $2.0 \pm 0.2$ & $116 \pm 0.34$ \\
\hline & 0.1 & $4.0 \pm 0.1$ & $11 \pm 0.2$ & $1.2 \pm 0.2$ & $113.3 \pm 0.34$ \\
\hline \multirow{2}{*}{$k-\varepsilon$ standard } & 0.2 & 3.9 & 9.3 & 2.3 & 110.91 \\
\hline & 0.1 & 4.0 & 10.9 & 1.3 & 109.48 \\
\hline \multirow{2}{*}{$k-\varepsilon R N G$} & 0.2 & 3.9 & 5.1 & 1.4 & 112.66 \\
\hline & 0.1 & 4.0 & 7.2 & 0.9 & 110.83 \\
\hline \multirow{2}{*}{$k-\varepsilon R N G$ (swirl) } & 0.2 & 3.9 & 4.1 & 1.1 & 113.75 \\
\hline & 0.1 & 4.0 & 5.9 & 0.8 & 111.70 \\
\hline \multirow{2}{*}{$k-\omega S S T$} & 0.2 & 3.9 & 8.8 & 2.3 & 113.58 \\
\hline & 0.1 & 4.0 & 10.7 & 1.3 & 111.75 \\
\hline \multirow{2}{*}{$k-\omega$ standard } & 0.2 & 3.9 & 4.1 & 1.1 & 113.75 \\
\hline & 0.1 & 4.0 & 8.6 & 1.1 & 110.21 \\
\hline
\end{tabular}

The standard $k-\varepsilon$ model is a wildly adopted turbulence model. The turbulence kinetic energy $k$ and the rate of dissipation $\varepsilon$, can be obtained from the following transport equations ${ }^{[22]}$ :

$$
\begin{gathered}
\frac{\partial(\rho k)}{\partial t}+\frac{\partial\left(\rho k u_{\mathrm{i}}\right)}{\partial x_{\mathrm{i}}}=\frac{\partial}{\partial x_{\mathrm{j}}}\left[\left(\mu+\frac{\mu_{t}}{\sigma_{k}}\right) \frac{\partial k}{\partial x_{\mathrm{j}}}\right]+G_{k}+G_{b}-\rho \varepsilon-Y_{M}+S_{k} \\
\frac{\partial(\rho \varepsilon)}{\partial t}+\frac{\partial\left(\rho \varepsilon u_{\mathrm{i}}\right)}{\partial x_{\mathrm{i}}}=\frac{\partial}{\partial x_{\mathrm{j}}}\left[\left(\mu+\frac{\mu_{t}}{\sigma_{\varepsilon}}\right) \frac{\partial \varepsilon}{\partial x_{\mathrm{j}}}\right]+C_{1 \varepsilon} \frac{\varepsilon}{k}\left(G_{k}+C_{3 \varepsilon} G_{b}\right)-C_{2 \varepsilon} \rho \frac{\varepsilon^{2}}{k}+S_{\varepsilon}
\end{gathered}
$$

where $G_{k}$ is the generation of turbulence kinetic energy from the mean velocity gradients; $G_{b}$ is the generation of turbulence kinetic energy from buoyancy; $Y_{M}$ is the contribution of the fluctuating dilatation in compressible turbulence to the overall dissipation rate; $C_{1 \varepsilon}, C_{2 \varepsilon}, C_{3 \varepsilon}$ are constants; $\sigma_{k}$ and $\sigma_{\varepsilon}$ are the turbulent Prandtl numbers for $k$ and $\varepsilon ; S_{k}$ and $S_{\varepsilon}$ are user-defined source terms. 
$\mu_{t}$ is the turbulent viscosity, which can be calculated from $k$ and $\varepsilon$ as follows:

$$
\mu_{t}=\rho C_{\mu} \frac{k^{2}}{\varepsilon}
$$

$C_{\mu}=0.09, C_{1 \varepsilon}=1.44, C_{2 \varepsilon}=1.92, \sigma_{k}=1.0, \sigma_{\varepsilon}=1.3$

\section{Results and discussions}

\subsection{Influence of the cold mass flow ratio $\mu_{\mathrm{c}}$ on TSE}

At a fixed $\dot{m}_{\text {in }}$ of $4.1 \mathrm{~g} / \mathrm{s}$ and $T_{\text {in }}$ of $22{ }^{\circ} \mathrm{C}$, the $\mu_{\mathrm{c}}$ is varied from 0.1 to 0.9 by changing the hot end pressure $p_{\mathrm{h}}$ while the cold end pressure $p_{\mathrm{c}}$ is kept constant at $1 \mathrm{~atm}$. When the $p_{\mathrm{h}}$ is varied, the pressure drop through the VT will change, thus resulting a corresponding change in $p_{\text {in. }}$ On the other hand, for a fixed $p_{\text {in }}$, the $\dot{m}_{\text {in }}$ will change when $p_{\mathrm{h}}$ is varied.

Figure 4 presents the cooling and heating effect. Similar to others ${ }^{[9,25]}$, the decrease of the $\mu_{\mathrm{c}}$ leads to an increase of the cooling effect, and the heating effect increases with increasing the $\mu_{\mathrm{c}}$. At a given $\mu_{\mathrm{c}}$, compared to R134a and R600, air has a much larger cooling/heating effect that are also more sensitive to the changes in $\mu_{\mathrm{c}}$. For the cooling effect, R600 performs marginally better than R134a, though their heating effects are very similar across the $\mu_{\mathrm{c}}$ range.

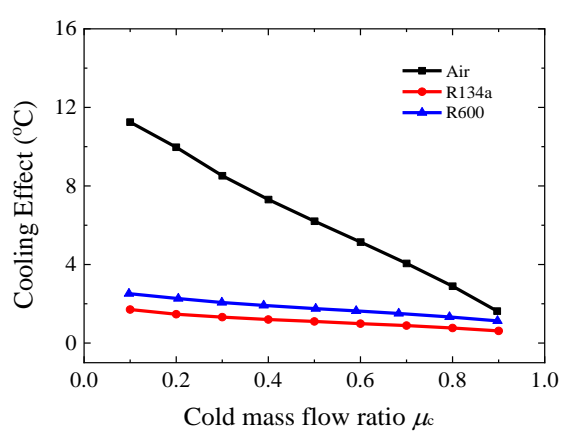

a

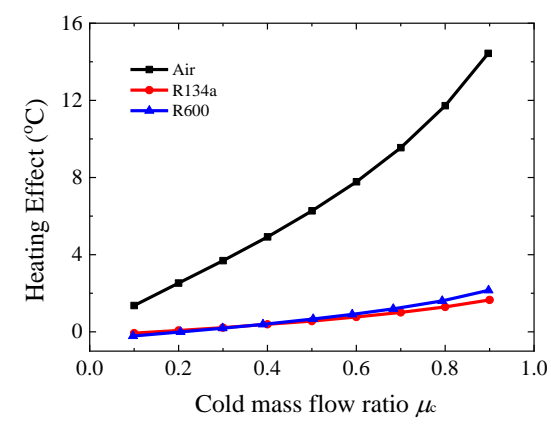

b

Figure 4 Variations of cooling effect (a) and heating effect (b) with the $\mu_{\mathrm{c}}$ for air, R134a and R600

For a given $\mu_{\mathrm{c}}$ and $\dot{m}_{\mathrm{in}}$, the air has a much higher inlet velocities $v_{\text {cham_in }}$ (Figure 5) due to being lighter than two refrigerants. Qualitatively all three fluids have rather similar shear stress distribution profiles (Figure 6). For a given fluid and $\mu_{\mathrm{c}}$, the values of $\tau_{w \mathrm{y}}$ are much larger than $\tau_{w \mathrm{x}}$, suggesting that the tangential shear stresses in the radial direction $\left(\tau_{w y}\right)$ have a much stronger influence on the TSE than that of $\tau_{w x}$. Air has considerably larger $\tau_{w y}$ than R134. All these contribute to producing a stronger rotation and more friction, thus delivering a larger temperature change during the rotation process ${ }^{[3,25,26]}$ for air.

The pressure drops between VT inlet and cold end $\left(\Delta p_{\text {in-c }}\right) \&$ hot end $\left(\Delta p_{\text {in-h }}\right)$ need to be considered too, as the fluid will encounter a temperature drop due to these pressure drops when they spiral/expand toward the cold and hot end. For the cooling effect, the temperature drop from the $\Delta p_{\text {in-c }}$ can be regarded as complementary to the temperature decrease from the rotation, whereas the $\Delta p_{\text {in-h }}$ can cancel the temperature increase from the rotation. Relative to the chosen refrigerants, a $\Delta p_{\text {in-c }}$ (Figure $7 \mathrm{a}$ ) for air produces correspondingly a larger temperature drop caused by the expansion process. Accordingly, air has the largest cooling effect.

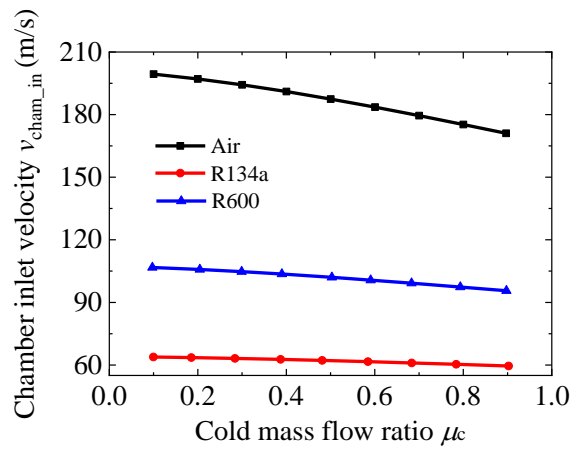

Figure 5 Chamber inlet velocities for air, R134a and R600 


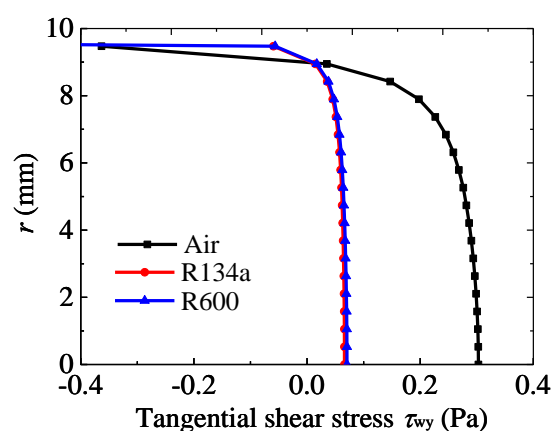

a

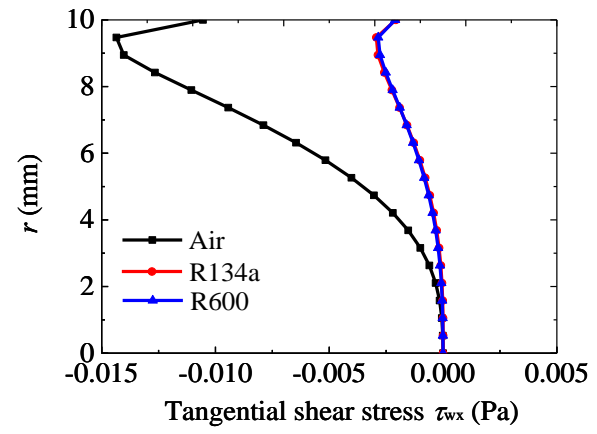

b

Figure 6 Tangential shear stress at the CS $(x=20 \mathrm{~mm})$ in (a) $y /$ radial and (b) $x / a x i a l$ directions for air, R134a and $\operatorname{R600}\left(\mu_{\mathrm{c}}=0.5\right)$

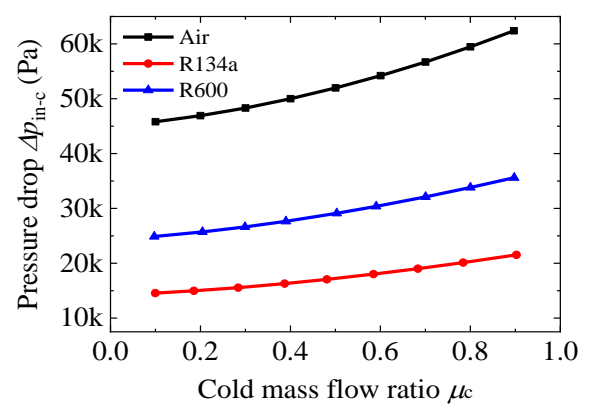

a

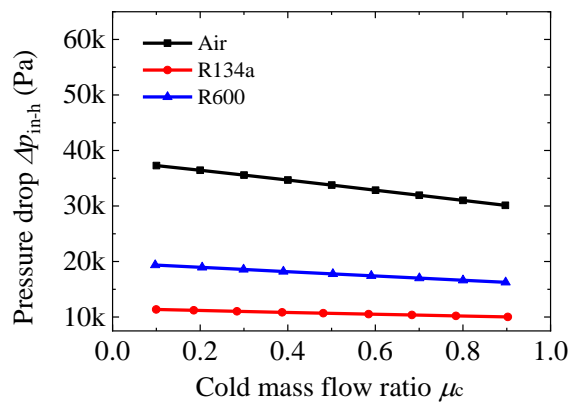

b

Figure 7 Pressure drop between the VT inlet and the cold/hot end for three fluids

In Figure $7 \mathrm{~b}$, air has a larger $\Delta p_{\text {in-h }}$ and therefore the associated temperature drop could potentially cancel out relatively more heating effect when compared to R134a and R600. However, it still produces the biggest heating effect. This suggests the temperature increase from the rotational friction, as influenced by the chamber inlet velocity/shear stress, is significantly larger than the temperature drop caused by the flow expansion $\left(\Delta p_{\text {in-c }}\right)$ under the specified conditions. Regardless of the value of $\mu_{\mathrm{c}}$, R600 always has a larger $v_{\text {cham_in }}$ and $\Delta p_{\text {in-c }}$ than $\mathrm{R} 134 \mathrm{a}$, leading to R600 having a larger cooling effect. However, it also has a larger $\Delta p_{\text {in-h }}$, resulting in a larger cancellation of the heating effect, thus resulting in them having similar values of heating effect.

It can be noted in Figure $6 \mathrm{~b}$ that $\mathrm{R} 600$ has a slight negative heating effect when the $\mu_{\mathrm{c}}$ drops to below 0.2 . It is believed that under this condition, the temperature drop due to $\Delta p_{\text {in-h }}$ is larger than the temperature increase produced by the rotational friction. This is supported by the estimates of isentropic and isenthalpic temperature drops (shown in Table 3) which increase with decreasing $\mu_{\mathrm{c}}$, when the $\Delta p_{\text {in-h }}$ is increased. It is widely believed that the temperature drop in the VT is larger than the isenthalpic temperature drop ${ }^{[27,28]}$, but lower than isentropic temperature drop, as friction is generated.

Table 3 Isentropic and isenthalpic temperature drop corresponding to the pressure drop $\Delta p_{\text {in-h }}$ for R600

\begin{tabular}{cccc}
\hline$\mu_{\mathrm{c}}$ & $\begin{array}{c}\text { Pressure drop, } \Delta p_{\text {in-h }} \\
\mathrm{kPa}\end{array}$ & $\begin{array}{c}\text { Isentropic temperature } \\
\text { drop } /{ }^{\circ} \mathrm{C}\end{array}$ & $\begin{array}{c}\text { Isenthalpic temperature } \\
\text { drop } /{ }^{\circ} \mathrm{C}\end{array}$ \\
\hline 0.1 & 1.94 & 4.44 & 0.51 \\
0.2 & 1.89 & 4.30 & 0.50 \\
0.3 & 1.86 & 4.18 & 0.49 \\
0.4 & 1.82 & 4.06 & 0.48 \\
0.5 & 1.78 & 3.92 & 0.47 \\
0.6 & 1.74 & 3.80 & 0.47 \\
0.7 & 1.71 & 3.67 & 0.45 \\
0.8 & 1.67 & 3.52 & 0.44 \\
0.9 & 1.63 & 3.40 & 0.44 \\
\hline
\end{tabular}


Figure 8 presents the streamlines and velocity vectors of the fluids at $\mu_{\mathrm{c}}=0.5$. They all have rather similar streamline patterns suggesting, for a given VT, the flow pattern is not too sensitive to the fluid choice. When the fluid enters the VT chamber, it spirals along the axial direction from the inlet (higher pressure) towards the hot end (lower pressure). At any radial CS, the primary flow can be regarded as combining of two movements, an outward and an inward movement (also seen in [29]). In the former, the flow rotates around the axis and leaves at the hot end, forming the hot stream. In the latter, the flow spirals inwardly towards the throttle.

In the radial direction, the inward flow movement undergoes an adiabatic expansion due to the pressure differential between the peripheral and inner parts. This flow process is similar to the angular propulsion process for a rotating flow ${ }^{[30]}$, in which the element both rotates around and moves toward the rotating centre. At the turning points, the inward flow (the primary flow) turn around and become the secondary flow moving towards the cold end due to pressure differential. When the secondary flow approaches the cold orifice, the outer part of the secondary flow recirculates (within the red dashed circle) and mixes with the primary flow due to the centrifugal force. This could convey the energy to the primary flow ${ }^{[15]}$.
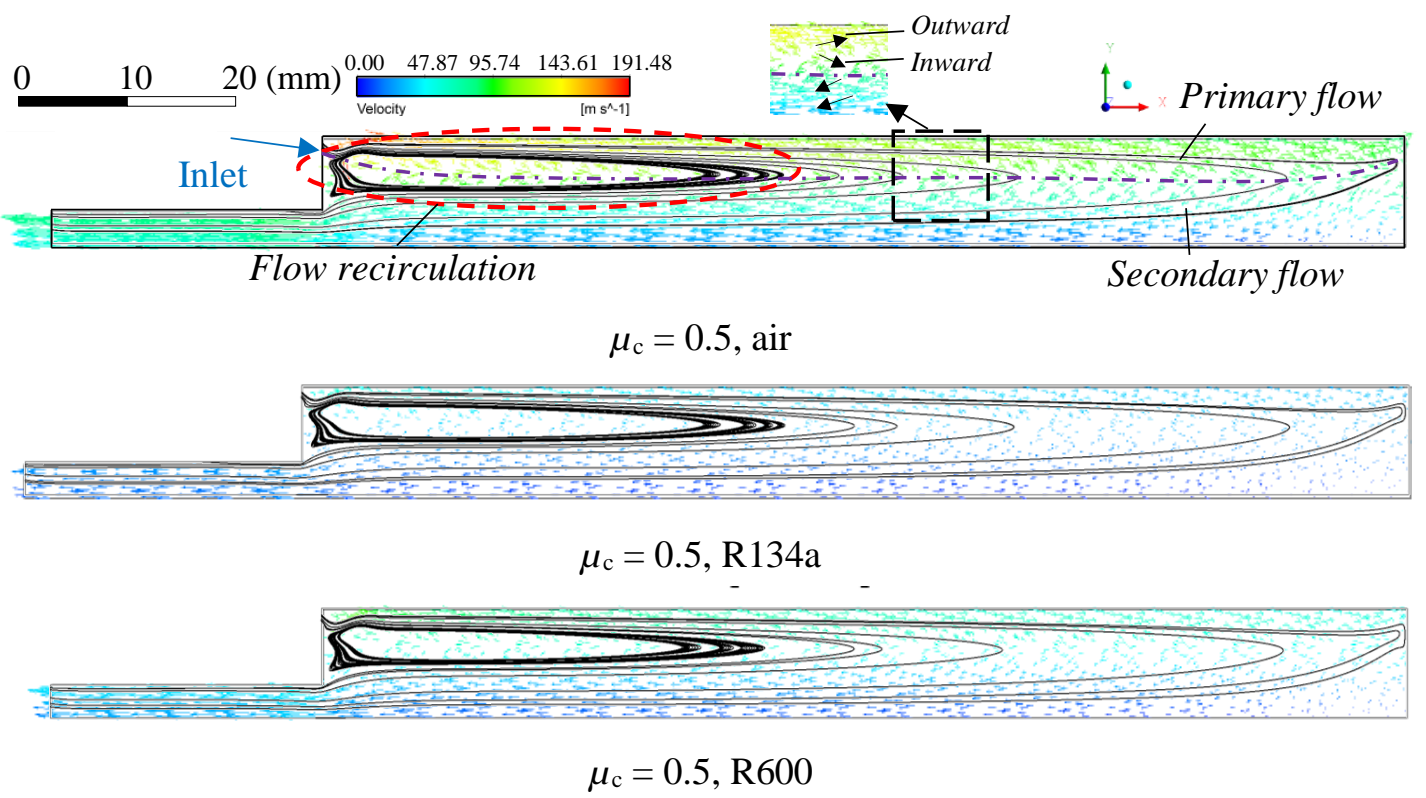

Figure 8 Streamlines for air, R134a and R600

Figure 9a-d show the temperature distributions within the VT at two $\mu_{\mathrm{c}}(=0.1$ for cooling and 0.9 for heating) for air and R600. In general, the temperature distributions of R600 (and R134a has the similar distribution, results not included in this paper) are very similar to that of air and to other researchers' ${ }^{[31,32]}$ too. The temperature decreases along the axis from the hot end towards the cold end, and increases radially outwards across any cross sections. However, at $\mu_{\mathrm{c}}=0.1$, local warm spots are noted at the cold end (Figure $9 \mathrm{a}$ and $\mathrm{c}$ for air and R600 ${ }^{1}$, respectively). These are caused by small flow recirculation as exemplified in the velocity vectors plots of R600 (Figure 10), and these are expected to have a slight impact on the VT cooling performance. At a small $\mu_{\mathrm{c}}$, the fluid could not flow evenly through the cold end, thus leading to some low-pressure regions at the cold end (red dash circle). The outside fluid (specified at $1 \mathrm{~atm}$ and $20{ }^{\circ} \mathrm{C}$ in CFD setup) can flow into this lowpressure region, but it turns around at the point when it has the same pressure to fluid from the secondary flow. Similar flow recirculation has also been observed by other researches in CFD works ${ }^{[33-35]}$. At very small $\mu_{\mathrm{c}}(\mathrm{e} . \mathrm{g}$. 0.01 ), this flow recirculation would be much bigger, as noted in [36].

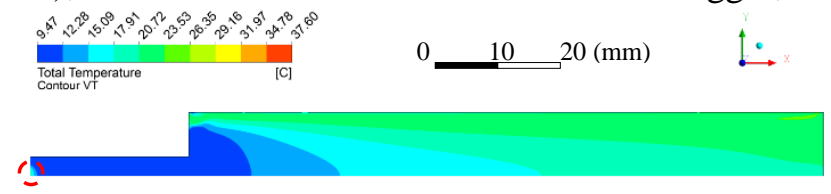

a. $\mu_{\mathrm{c}}=0.1$, air

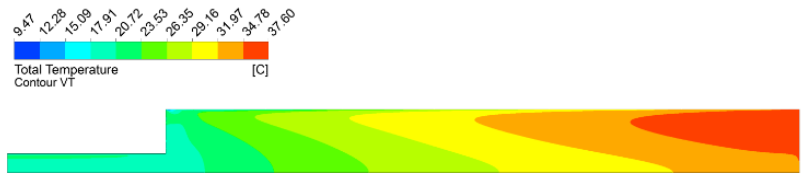

b. $\mu_{\mathrm{c}}=0.9$, air

\footnotetext{
${ }^{1}$ Local warm spot also appears at the cold end for R134a at $\mu_{\mathrm{c}}=0.1$
} 


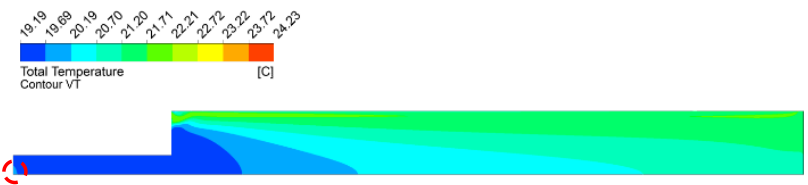

c. $\mu_{\mathrm{c}}=0.1$, R600 $\mu_{\mathrm{c}}=0.9, \mathrm{R} 600$
Figure 9 Temperature distribution at different cold mass flow ratios

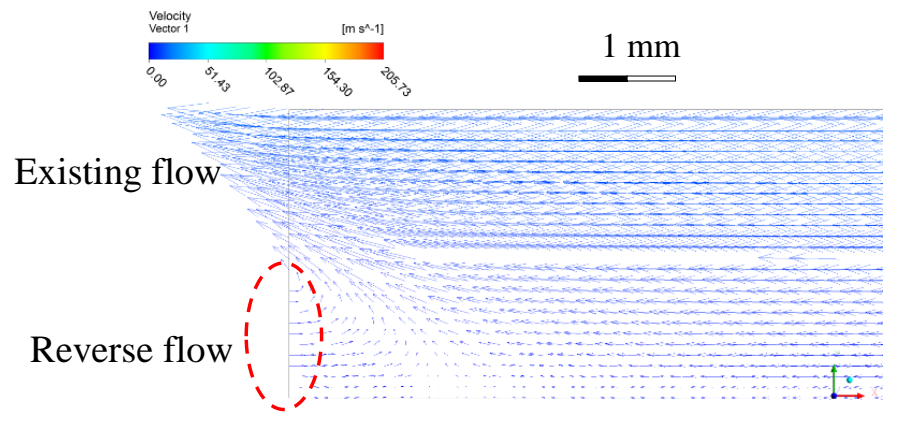

Figure 10 Velocity vectors near the cold end at $\mu_{\mathrm{c}}=0.1$ for R600

When the $\mu_{\mathrm{c}}$ is decreased to a very small value, a critical point (around $0.02 \sim 0.05$ ) leading to a maximum cooling effect for air and R600 can be observed (as indicated in Figure 11). The subsequent decrease of the cooling effect (calculated based on mass flow averaged at the exit plane, as illustrated in Figure 10) is believed to be caused mainly by the increase in reverse flow (set at $20^{\circ} \mathrm{C}$ atmosphere temperature) at the cold end when the exiting flow is very small. However, the critical point for R134a has yet to be observed at $\mu_{\mathrm{c}}=0.02$, due to the main exiting flow having a similar temperature to the reverse flow. (Note: $T_{\text {in }}$ is $22{ }^{\circ} \mathrm{C}$, main exiting flow is at $20^{\circ} \mathrm{C}$, reverse flow is at $20^{\circ} \mathrm{C}$, mass averaged at $20^{\circ} \mathrm{C}, \Delta T_{\mathrm{c}}=2{ }^{\circ} \mathrm{C}$, hence no critical point). However it is expected that if the $\mu_{\mathrm{c}}$ for R134a was to drop further, the influence of the main exiting flow on the mass average temperature would be weaker than the reverse flow, resulting in a critical point.

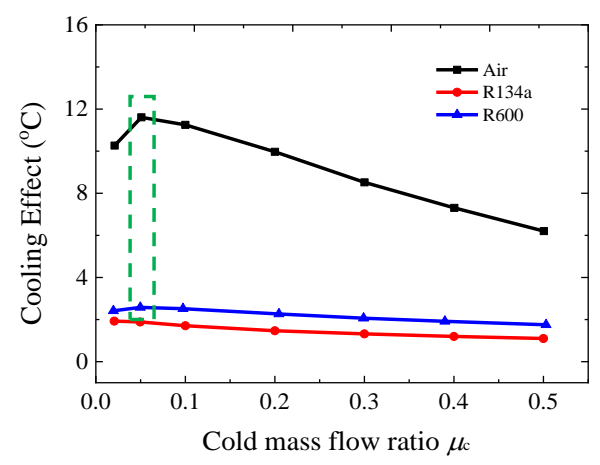

Figure 11 The cooling effect with the $\mu_{\mathrm{c}}$ (around $0.02 \sim 0.5$ ) for air, R134a and R600

\subsection{Influence of inlet pressure $p_{\text {in }}$ on TSE}

The fluids' cooling effect under a range of $p_{\text {in }}$ between $150 \mathrm{kPa}$ and $350 \mathrm{kPa}$ is presented in Figure 12 (Figure 16 for heating effect); $T_{\text {in }}$ is kept at $22{ }^{\circ} \mathrm{C}$, and both the hot end and the cold pressures are adjusted to achieve the required $\mu_{\mathrm{c}}$ between 0.1 and 0.9 . Though all three fluids share some common trends, individually they have certain distinctive features. 


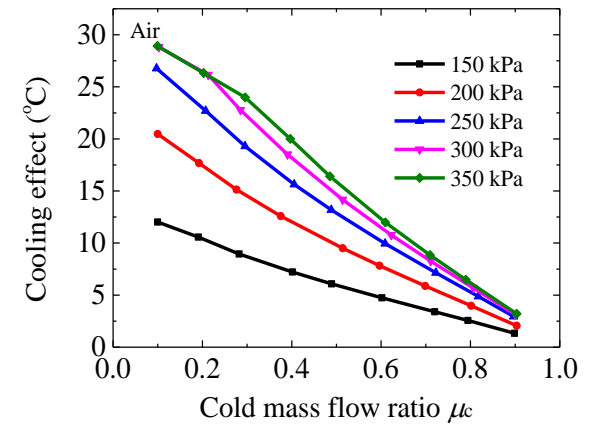

a

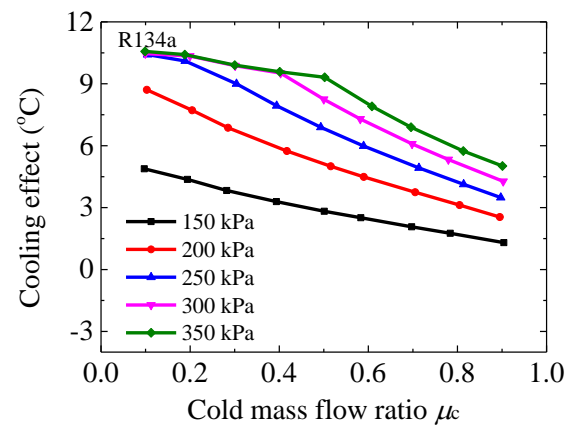

b

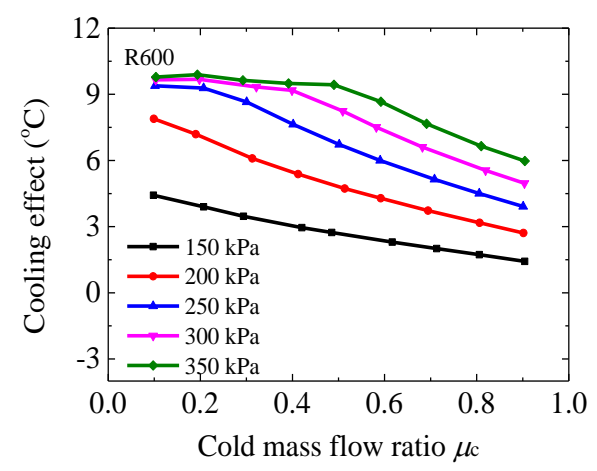

$\mathrm{c}$

Figure 12 Cooling effect under different inlet pressures of air (a), R134a (b) and R600 (c), $T_{\text {in }}=22{ }^{\circ} \mathrm{C}$

\subsubsection{The cooling effect}

At a relatively low $p_{\text {in, }}$ the cooling effect increases with decreasing $\mu_{\mathrm{c}}$. And in general, this trend continues at higher $p_{\text {in. }}$ Air has a much higher rate of increase with respect to $\mu_{\mathrm{c}}$ when compared to R134a and R600. However, as the $p_{\text {in }}$ increases, the rate drops off at a certain $\mu_{\mathrm{c}}$ value. At $300 \mathrm{kPa}$, the rate drops off at around $\mu_{\mathrm{c}}$ equals to $0.2,0.4$ and 0.4 respectively for air, R134a and R600. When the $p_{\text {in }}$ is increased further to $350 \mathrm{kPa}$, the corresponding rate drops off at a higher $\mu_{\mathrm{c}}$ value $-0.3,0.5$ and 0.5 .

For a given $\mu_{\mathrm{c}}$, in general the cooling effect increases with increasing $p_{\text {in }}$, but the exact pattern would depend on the fluid choice and the $\mu_{\mathrm{c}}$ value. For air, it appears that at a high $\mu_{\mathrm{c}}(=0.9)$, the cooling effect only increases by a small margin when the $p_{\text {in }}$ is gradually raised. At a small $\mu_{\mathrm{c}}(=0.1)$, much larger increases can be noted but it will stop increasing when a certain $p_{\text {in }}$ is reached. For R134a and R600, a similar pattern is noted at small $\mu_{\mathrm{c}}$ values, but at a high $\mu_{\mathrm{c}}(=0.9)$, relatively the cooling effect is more sensitive to the changes in the $p_{\text {in }}$ when compared to air. The above behaviour could be related to changes in the VT $v_{\text {cham_in }}$ (Figure 13), shear stress distributions (Figure 14), and the $\Delta p_{\mathrm{in}-\mathrm{c}}$ (Figure 15). $\tau_{\mathrm{wx}}$ is not shown as they are much smaller than $\tau_{\mathrm{wy}}$. All three fluids are found to have the similar $\Delta p_{\text {in-c }}$, while air has the largest VT $v_{\text {cham_in }}$ and shear stresses.

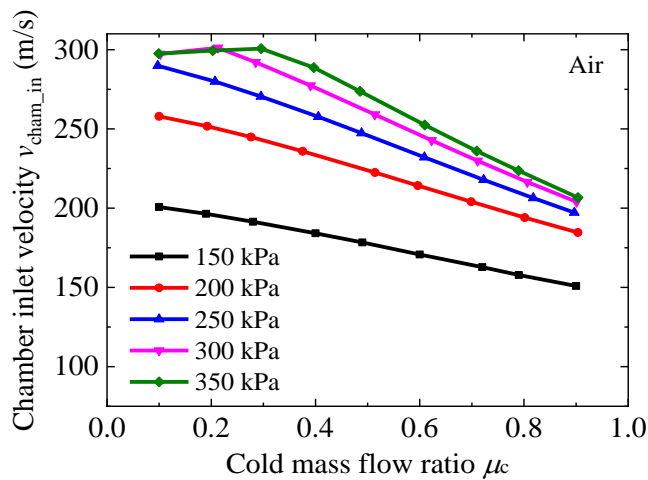

a

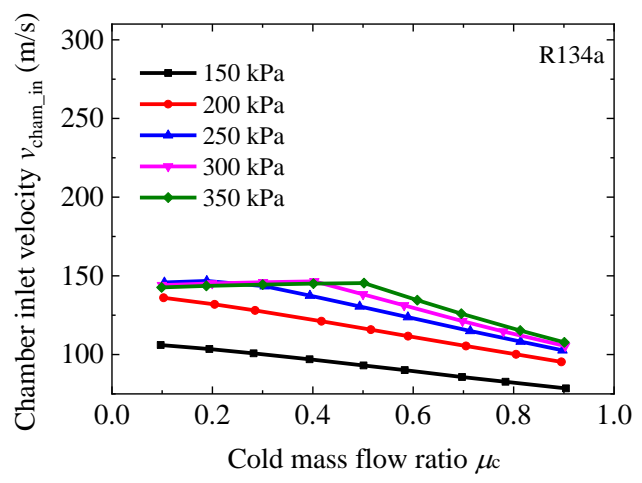

b 


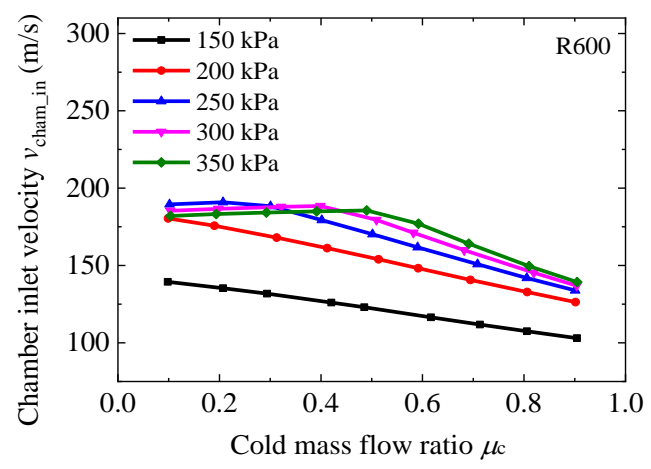

C

Figure 13 Inlet velocities of the VT chamber under different inlet pressure: air (a), R134a (b) and R600 (c)

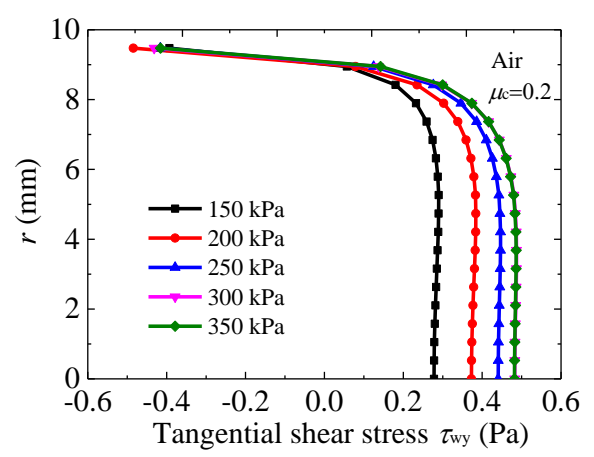

a

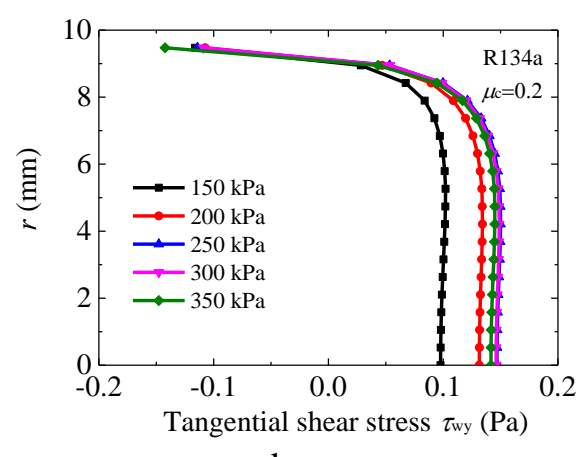

b

Figure 14 Shear stress distributions at the CS ( $\mathrm{x}=20 \mathrm{~mm}$ ) at $\mu_{\mathrm{c}}=0.2$ of air (a), R134a (b) (quantitatively tangential shear stress distributions for R600 are very similar to R134a, not shown)

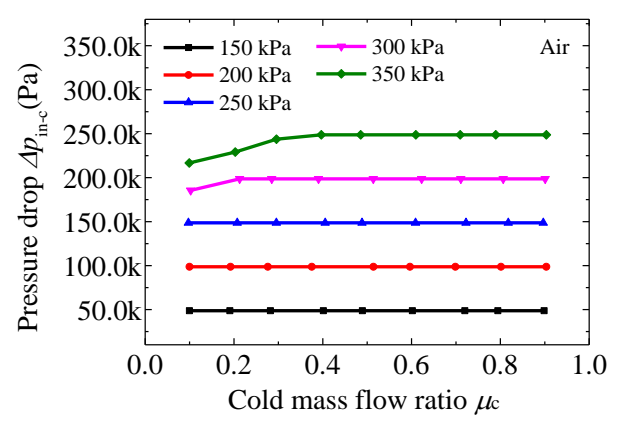

a

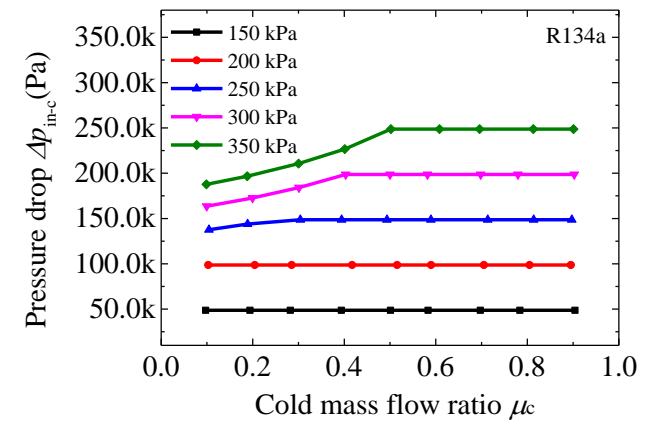

b

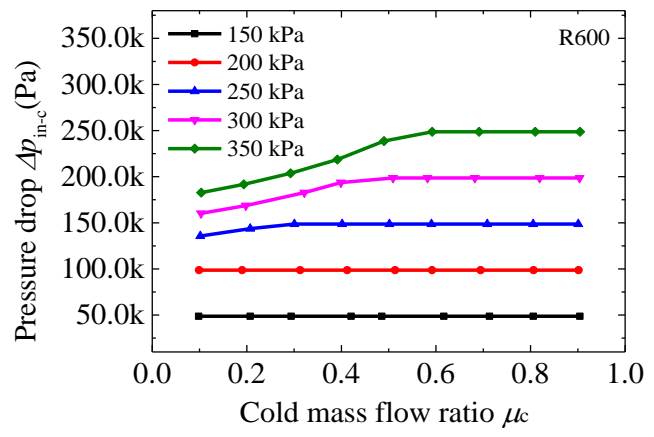

$\mathrm{c}$

Figure 15 Pressure drops $\Delta p_{\text {in-c }}$ for air (a), R134a (b) and R600 (c)

As seen in Figure 13, at any $\mu_{\mathrm{c}}$ larger than 0.3 for air, or 0.5 for R134a and R600, a higher $p_{\text {in }}$ would lead to a larger $v_{\text {cham_in }}$ and a stronger rotating flow. Figure 15 indicates that a higher $p_{\text {in }}$ always results in a larger $\Delta p_{\text {in-c }}$ 
which would produce a stronger adiabatic expansion in the VT. Their combined influence is to create a larger cooling effect when the $p_{\text {in }}$ is raised. However, for the same incremental increase $(50 \mathrm{kPa})$ of $p_{\text {in }}$, the corresponding incremental gains in the $v_{\text {cham_in }}$ are in fact diminishing (as shown in Figure 13). This results in smaller gains in the cooling effects as seen in Figure 12. The corresponding incremental changes in $\Delta p_{\text {in-c }}$ remain relative constant for the fluids when the $p_{\text {in }}$ is increased, as shown in Figure 15. This suggests the rotating flow, when compared to the expansion process, is the dominating factor for generating the TSE.

For smaller $\mu_{\mathrm{c}}$ (less than 0.3 for air, and less than 0.5 for R134a and R600), there is also an initial increase of the $v_{\text {cham }}$ in and $\tau_{\text {wy }}$ as well as an increase in $\Delta p_{\text {in-c }}$ when the $p_{\text {in }}$ is raised. However up to a certain value of $p_{\text {in }}(300$ $\mathrm{kPa}$ for air; $250 \mathrm{kPa}$ for R134a and R600), when the $v_{\text {cham_in }}$ approach the sonic or chocked condition, beyond which any further increases of the $p_{\text {in }}$ would bring a small drop of $v_{\text {cham_in }}$ and only a small increase in $\Delta p_{\text {in-c. }}$. Therefore, as a net result, the cooling effect only increases initially and remains relatively unchanged at higher $p_{\text {in. }}$.

\subsubsection{The heating effect}

In response to increasing $p_{\text {in }}$, both $\mathrm{R} 134 \mathrm{a}$ and $\mathrm{R} 600$ behave rather differently when compared to air, though in general for a given pressure, the heating effect increases with increasing $\mu_{\mathrm{c}}$.

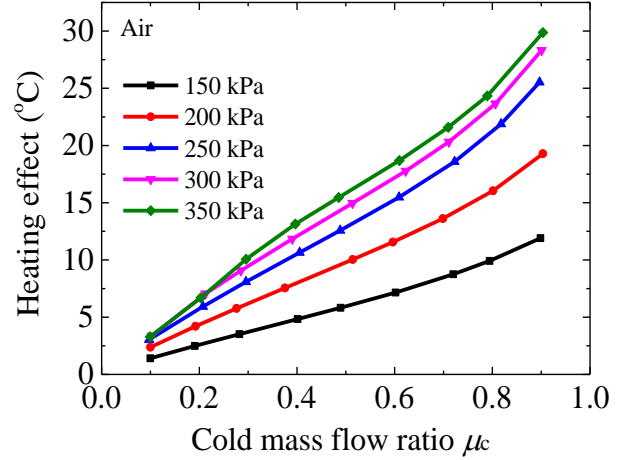

a

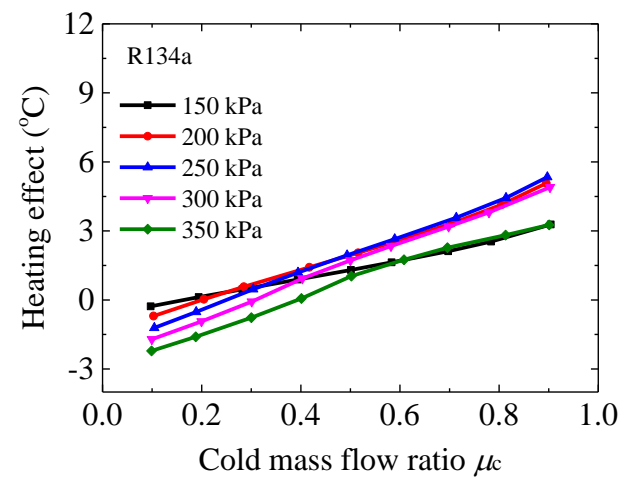

b

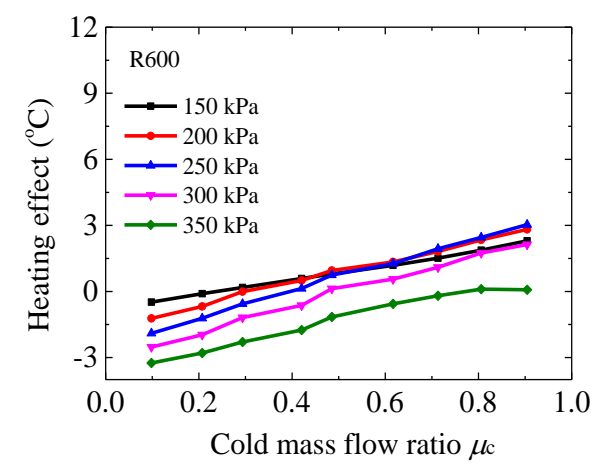

c

Figure 16 Heating effect under different inlet pressures of air (a), R134a (b) and R600 (c), $T_{\text {in }}=22{ }^{\circ} \mathrm{C}$

For air, an increase of $p_{\text {in }}$ produces an increase of the heating effect, though the net gain is progressively diminishing; this is closely linked to the increasing $v_{\text {cham }}$ in as previously presented. Although the corresponding $\Delta p_{\text {in-h }}$ (Figure 17) is also increasing, resulting in a larger temperature drop, the influence is not strong enough to cancel out the heating effect.

For R134a and R600, in general at $\mu_{\mathrm{c}}$ less than $0.4 \sim 0.5$, the heating effect decreases with increasing $p_{\text {in. }}$ This leads to little or even negative heating effects; a similar observation was made in [14]. It also appears that at a low $p_{\text {in }}(150 \mathrm{kPa})$, the heating effect changes at a relatively lower rate with respect to $\mu_{\mathrm{c}}$, leading to it crossing other trend lines. These observations however may not have any practical significance as a VT will normally operate at high $\mu_{\mathrm{c}}$ values when used as a heating device. 


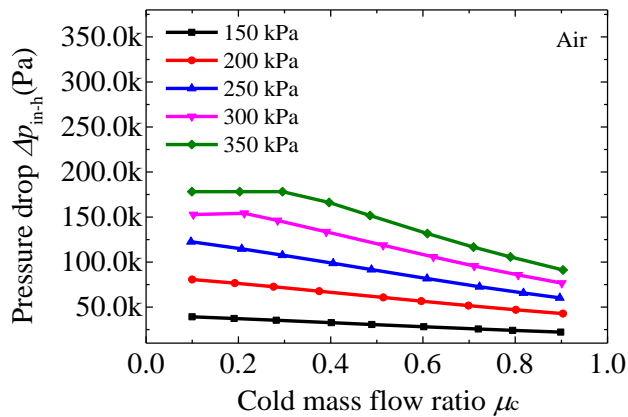

a

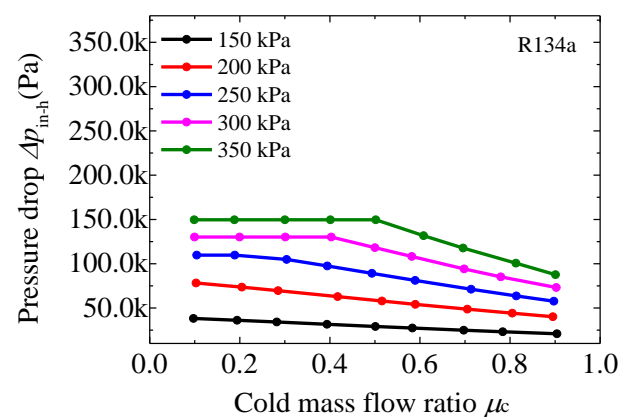

b

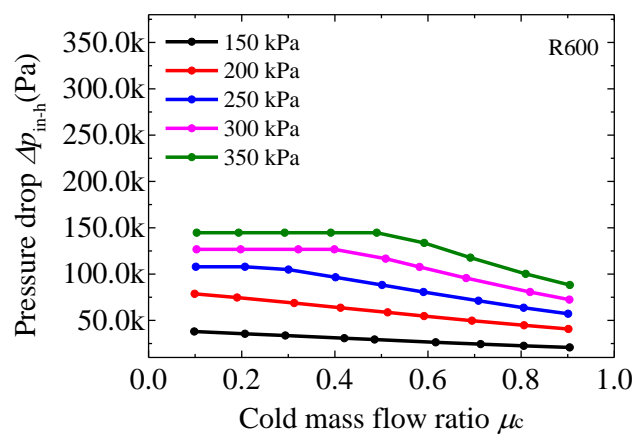

$\mathrm{C}$

Figure 17 Pressure drops $\Delta p_{\text {in-h }}$ for air (a), R134a (b) and R600 (c)

For $p_{\text {in }}$ above $150 \mathrm{kPa}$ pressure, a more recognisable trend emerges for $\mu_{\mathrm{c}}$ values larger than 0.5 . When $p_{\text {in }}$ is increased, there are only little changes in the heating effect until reaching certain higher-pressure value, then one would see noticeable drops in the heating effect. As seen for R600, when the $p_{\text {in }}$ is raised to $350 \mathrm{kPa}$, the heating effect has completely disappeared (i.e. negative heating effect). All three fluids share a similar trend (Figure 17) that a bigger $\Delta p_{\text {in-h }}$ is experienced at a higher $p_{\text {in }}$.

To understand the causes of the differences in the heating effects between the air and the refrigerants, additional CFD simulations are run with the following two boundary conditions.

- The fluid enters the VT chamber in $\mathrm{x}$-direction with zero $\mathrm{y}$ and $\mathrm{z}$ velocity components - referred as a "Straight" run. The cold end is closed as a "wall" boundary setup in Fluent, i.e. one inlet and one outlet flow configuration and thus no TSE is generated. The associated temperature drop is expected to be purely a result of thermal expansion due to pressure drop.

- The fluid enters the VT chamber with prescribed $\mathrm{x}, \mathrm{y}$ and $\mathrm{z}$ velocity components - referred as a "Rotation" run. The cold end still remains closed as above and thus no TSE is expected.

The two runs are to calculate the temperature drops $(\Delta T)$, Table 4 , between the VT inlet and the hot end caused by the same $\Delta p_{\text {in-h }}$ values presented in Figure 15 at $\mu_{\mathrm{c}}=0.1$ and 0.7, for R134a and air.

Table 4 Temperature drop $(\Delta T)$ for R134a at the corresponding pressure drop $\Delta p_{\text {in-h }}\left(\mu_{\mathrm{c}}=0.1\right.$ and 0.7$)$

\begin{tabular}{c|cc|c|c|c|c|cc}
\hline \multirow{2}{*}{$p_{\text {in }}$} & \multicolumn{4}{|c|}{$\mathrm{R} 134 \mathrm{a}$} & \multicolumn{4}{c}{ Air } \\
& \multicolumn{2}{|c|}{$\Delta T\left({ }^{\circ} \mathrm{C}\right), \mu_{\mathrm{c}}=0.1$} & \multicolumn{2}{c}{$\Delta T\left({ }^{\circ} \mathrm{C}\right), \mu_{\mathrm{c}}=0.7$} & \multicolumn{2}{c}{$\Delta T\left({ }^{\circ} \mathrm{C}\right), \mu_{\mathrm{c}}=0.1$} & \multicolumn{2}{|c}{$\Delta T\left({ }^{\circ} \mathrm{C}\right), \mu_{\mathrm{c}}=0.7$} \\
$\mathrm{kPa}$ & Straight & Rotation & Straight & Rotation & Straight & Rotation & Straight & Rotation \\
\hline 150 & 0.47 & 0.71 & 0.31 & 0.45 & 0.0026 & 0.005 & 0.0008 & 0.001 \\
200 & 0.94 & 1.48 & 0.61 & 0.92 & 0.0030 & 0.008 & 0.0001 & 0.005 \\
250 & 1.32 & 2.11 & 0.88 & 1.34 & 0.0017 & 0.006 & 0.0003 & 0.006 \\
300 & 1.59 & 2.53 & 1.17 & 1.80 & 0.0002 & 0.007 & 0.0023 & 0.007 \\
350 & 1.86 & 2.94 & 1.48 & 2.29 & 0.0025 & 0.009 & 0.0017 & 0.008 \\
\hline
\end{tabular}


As air behaves close to ideal gas, there are hardly any temperature drops associated with the expansion process within the entire range of $p_{\text {in }}$, regardless what boundary conditions are used. Therefore, the heating effect achieved (Figure 15) is mainly a result of rotational friction. For the same pressure drop, when the "straight" and "rotation" runs are compared, it appears that the temperature drop due to thermal expansion could achieve a bigger value when the rotational flow is involved.

For refrigerants, a higher $\mu_{\mathrm{c}}$ always produces a smaller temperature drop, indicating correspondingly a smaller temperature cancelling of the heating effect is expected. Compared to air, the temperature drops of R134a are always much bigger, suggesting it could potentially cancel out a larger part of the energy gained due to rotation. This results in a small or even negative heating effect (Figure 16b). This is particular the case for small $\mu_{\mathrm{c}}$ values when $p_{\text {in }}$ exceeds certain values at which the $v_{\text {cham in }}$ decreases (Figure 13), and at the same time, the pressure drop $\Delta p_{\text {in-h }}$ (Figure 17) keeps increasing. At higher $\mu_{\mathrm{c}}$ values, however, when the $p_{\text {in }}$ increases, and since both of the $v_{\text {cham_in }}$ (Figure 13) and $\Delta p_{\text {in-h }}$ increase, the heating effect could remain relatively unchanged, except when the inlet is raised above certain values then once again low or negative heating effects are possible. This result suggests that a high $p_{\text {in }}$ with a large $\Delta p_{\text {in-h }}$ can generate a small or even negative heating effect. On the hand, a small $p_{\text {in }}$ with a small $\Delta p_{\text {in-h }}$ has the possibility to produce relatively a large heating effect.

At $150 \mathrm{kPa} p_{\text {in }}$, the corresponding $v_{\text {cham_in }}$ is too low to be effective for generating a good heating effect. This suggests that for R134a and R600, either too low or too high $p_{\text {in }}$ could lead to poor VT heating performance.

\section{Conclusions}

The thermal behaviour of air R134a and R600 in a VT under different operating conditions are numerically compared, and their cooling and heating effects are analysed. Some conclusions can be drawn.

- Air, R134a and R600 are found to have rather similar trends in their VT cooling effect. At a given $\mu_{\mathrm{c}}$ and $p_{\mathrm{c}}$, an increase in $p_{\text {in }}$ generally leads to an increase in cooling effect, though the rate of increase is diminishing when the chamber inlet velocities approach the sonic or chocked condition. At the same VT inlet $\dot{m}_{\text {in }}$ or/and $p_{\text {in }}$ condition, air has a considerable larger cooling or heating effect, as its velocities and shear stress are larger than that of the other two fluids.

- The flow streamlines appear not to be sensitive to the fluid choices. Qualitatively the trends for the shear stress of air and the refrigerants are rather similar. For a given fluid and $\mu_{\mathrm{c}}$, the tangential shear stress in the radial direction ( $\left.\tau_{\mathrm{wy}}\right)$ has a much stronger influence on the TSE than that of $\tau_{\mathrm{wx}}$.

- Air and the refrigerants are found to have their unique trends in VT heating effect. Continue increase of the VT inlet pressure could decrease the heating effect for the refrigerants, and the pressure drop in the VT plays a more important role in determining the heating effect for refrigerants than for air. The temperature increase from the rotating friction cancelled by the temperature drop due to expansion is much more for refrigerants than air.

\section{References}

1. Subudhi, S. and M. Sen, Review of ranque-hilsch vortex tube experiments using air. Renewable \& Sustainable Energy Reviews, 2015. 52: p. 172-178.

2. Kirmaci, V. and O. Uluer, An experimental investigation of the cold mass fraction, nozzle number, and inlet pressure effects on performance of counter flow vortex tube. Journal of Heat Transfer-Transactions of the Asme, 2009. 131(8): p. 081701.

3. Eiamsa-ard, S., Experimental investigation of energy separation in a counter-flow Ranque-Hilsch vortex tube with multiple inlet snail entries. International Communications in Heat and Mass Transfer, 2010. 37(6): p. 637-643.

4. Ahlborn, B., J. Camire, and J.U. Keller, Low-pressure vortex tubes. Journal of Physics D-Applied Physics, 1996. 29(6): p. 1469-1472.

5. Saidi, M.H. and M.S. Valipour, Experimental modeling of vortex tube refrigerator. Applied Thermal Engineering, 2003. 23(15): p. 1971-1980.

6. Ahlborn, B., et al., Limits of temperature separation in a vortex tube. Journal of Physics D-Applied Physics, 1994. 27(3): p. 480-488.

7. Gulyaev, A.I., Ranque effect at low temperatures. Journal of engineering physics, 1965. 9(3): p. 242-244.

8. Ding, Y., Research of application of vortex tube in light hydrocarbon recovery technology. 2006, Beijing University of Technology: Beijing, China. 
9. Aydin, O. and M. Baki, An experimental study on the design parameters of a counterflow vortex tube. Energy, 2006. 31(14): p. 2763-2772.

10. Stephan, K., et al., An investigation of energy separation in a vortex tube. International Journal of Heat and Mass Transfer, 1983. 26(3): p. 341-348.

11. Promvonge, P. and S. Eiamsa-ard, Investigation on the vortex thermal separation in a vortex tube refrigerator. ScienceAsia, 2005. 31(3): p. 215-23.

12. Zhu, J., Experimental investigation of vortex tube and vortex nozzle for applications in air-conditioning, refrigeration, and heat pump systems, in Mechanical Science \& Engineering. 2015, University of Illinois at UrbanaChampaign.

13. Martynovskii, V. and V. Alekseev, Investigation of the vortex thermal separation effect for gases and vapors. Soviet Physics-Technical Physics, 1956. 1(10): p. 2233-2243.

14. Han, X., et al., The influence of working gas characteristics on energy separation of vortex tube. Applied Thermal Engineering, 2013. 61(2): p. 171-177.

15. Frohlingsdorf, W. and H. Unger, Numerical investigations of the compressible flow and the energy separation in the Ranque-Hilsch vortex tube. International Journal of Heat and Mass Transfer, 1999. 42(3): p. 415-422.

16. Karimi-Esfahani, M., A. Fartaj, and G. Rankin. Predicting optimum vortex tube performance using a simplified CFD model. in Twelfth annual conference of the CFD Society of Canada. 2004. Ottawa, Canada.

17. Aljuwayhel, N.F., G.F. Nellis, and S.A. Klein, Parametric and internal study of the vortex tube using a CFD model. International Journal of Refrigeration, 2005. 28(3): p. 442-450.

18. Behera, U., et al., Numerical investigations on flow behaviour and energy separation in Ranque-Hilsch vortex tube. International Journal of Heat and Mass Transfer, 2008. 51(25-26): p. 6077-6089.

19. Shamsoddini, R. and A.F. Khorasani, A new approach to study and optimize cooling performance of a Ranque-Hilsch vortex tube. International Journal of Refrigeration, 2012. 35(8): p. 2339-2348.

20. Dutta, T., K.P. Sinhamahapatra, and S.S. Bandyopdhyay, Comparison of different turbulence models in predicting the temperature separation in a Ranque-Hilsch vortex tube. International Journal of Refrigeration, 2010. 33(4): p. 783792.

21. Baghdad, M., et al., Numerical study of energy separation in a vortex tube with different RANS models. International Journal of Thermal Sciences, 2011. 50(12): p. 2377-2385.

22. ANSYS, I. ANSYS Fluent Theory Guide, Release 15.0. 2013.

23. Secchiaroli, A., et al., Numerical simulation of turbulent flow in a Ranque-Hilsch vortex tube. International Journal of Heat and Mass Transfer, 2009. 52(23-24): p. 5496-5511.

24. Pourmahmoud, N., F.S. Azar, and A. Hassanzadeh, Numerical simulation of secondary vortex chamber effect on the cooling capacity enhancement of vortex tube. Heat and Mass Transfer, 2014. 50(9): p. 1225-1236.

25. Hilsch, R., The use of the expansion of gases in a centrifugal field as cooling process. Review of Scientific Instruments, 1947. 18(2): p. 108-113.

26. Kassner, R. and E. Knoernschild, Friction laws and energy transfer in circular flow. Part 1-the law of shear stresses in circular flow. Part 2-energy transfer in circular flow and possible applications (explanation of the Hilsch or Ranque effect). 1948, DTIC Document.

27. Lorey, M., J. Steinle, and K. Thomas. Industrial application of vortex tube separation technology utilizing the Ranque-Hilsch effect. in European Petroleum Conference. 1998. The Hague, Netherlands: Society of Petroleum Engineers.

28. Xue, Y., et al., The expansion process in a counter flow vortex tube. Journal of Vortex Science and Technology, 2015. 2(1).

29. Behera, U., et al., CFD analysis and experimental investigations towards optimizing the parameters of Ranque-Hilsch vortex tube. International Journal of Heat and Mass Transfer, 2005. 48(10): p. 1961-1973.

30. Polihronov, J.G. and A.G. Straatman, Thermodynamics of angular propulsion in fluids. Physical Review Letters, 2012. 109(5): p. 054504.

31. Thakare, H.R. and A.D. Parekh, Computational analysis of energy separation in counter-flow vortex tube. Energy, 2015. 85: p. 62-77.

32. Manimaran, R., Computational analysis of flow features and energy separation in a counter-flow vortex tube based on number of inlets. Energy, 2017. 123: p. 564-578.

33. Skye, H.M., G.F. Nellis, and S.A. Klein, Comparison of CFD analysis to empirical data in a commercial vortex tube. International Journal of Refrigeration, 2006. 29(1): p. 71-80.

34. Thakare, H.R. and A.D. Parekh, Computational analysis of energy separation in counter-flow vortex tube. Energy, 2015. 85: p. 62-77.

35. Kandil, H.A. and S.T. Abdelghany, Computational investigation of different effects on the performance of the Ranque-Hilsch vortex tube. Energy, 2015. 84(0): p. 207-218.

36. Wang, Z., The research of the vortex tube performance and the coupling characteristics with the responding refrigeration system, in The department of Energy Engineering. 2013, Zhejiang University: Hangzhou, China. 